\title{
Simultaneous EBSD and EDS Characterization of Silver Kennedy Half Dollar Coins
}

\author{
Lisa H. Chan, Tara Nylese, Robert Anderhalt, Matthew Nowell and John Lorenzo
}

EDAX, Inc. Mahwah, NJ, USA

For numismatists, the capability to determine a coin's authenticity and place of origin is invaluable. While the alloy composition of the coins can reveal the coin's possible place of origin, the microstructure and crystallograhic nature of the coins can reveal the coin's thermo-mechanical history such as rolling, casting, and annealing, which can provide insight into the method of minting. The simultaneous collection of both electron backscatter diffraction (EBSD) and energy dispersive spectroscopy (EDS), provides the correlation of orientation and chemical data to specific microstructural features. Previous studies on silver-copper coins using EDS has shown that there is preferential silver enrichment at the surface of the coins [1].

The material used for this investigation was a U.S. Mint 1964 Kennedy Half Dollar coin that is composed of a silver-copper alloy. The silver coin was cross-sectioned and polished for microanalysis. The polishing procedure includes grinding with $\mathrm{SiC}$ papers from 320 to 1200 grit, polishing with $1 \mu \mathrm{m}$, $0.3 \mu \mathrm{m}$, and $0.05 \mu \mathrm{m}$ alumina, and a final polishing with $0.05 \mu \mathrm{m}$ colloidal silica on the vibratory polisher. The cross section was tilted to 70 degrees in a JEOL-7000 field-emission scanning electron microscope, at which point an EDAX Hikari Camera and Octane Plus Silicon Drift Detector were used to simultaneously collect EBSD and EDS information.

EDS analysis yields information about the elemental components while EBSD reveals the grain size, preferential crystallographic orientations, and local misorientations. However, the crystallographic structures present in the silver coin can only be differentiated when both techniques are performed simultaneously as with the EDAX Pegasus Chi-Scan technique [2]. The combination of the two analytical techniques provides further insight into the characterization of historical and modern coins.

The microstructure of the Kennedy Half Dollar coin shows phase separation with a silver-rich phase $(91 \% \mathrm{Ag}$ and $9 \% \mathrm{Cu}$ ), and a silver-copper phase $(53 \% \mathrm{Ag}$ and $47 \% \mathrm{Cu}$ ). The distribution of the two phases can be seen in Fig. 1. The orientation data from each of the phases can be seen in Fig. 2. Based on the orientation information observed, there is no preferential orientation relationship between the silver-rich and the silver-copper phases. However, the grain sizes of the two phases are very different, with the silver-rich and silver-copper phases having average grain sizes of $0.25 \mu \mathrm{m}$ and $0.17 \mu \mathrm{m}$ respectively.

\section{References:}

[1] L. Beck, S. Bosonnet, S. Réveillon, D. Eliot and F. Pilon, Nuclear Instruments and Methods in Physics Research, B226 (2004), p. 153-162.

[2] M. M. Nowell, and S.I. Wright, Journal of Microscopy 213 (2004), p. 296-305. 


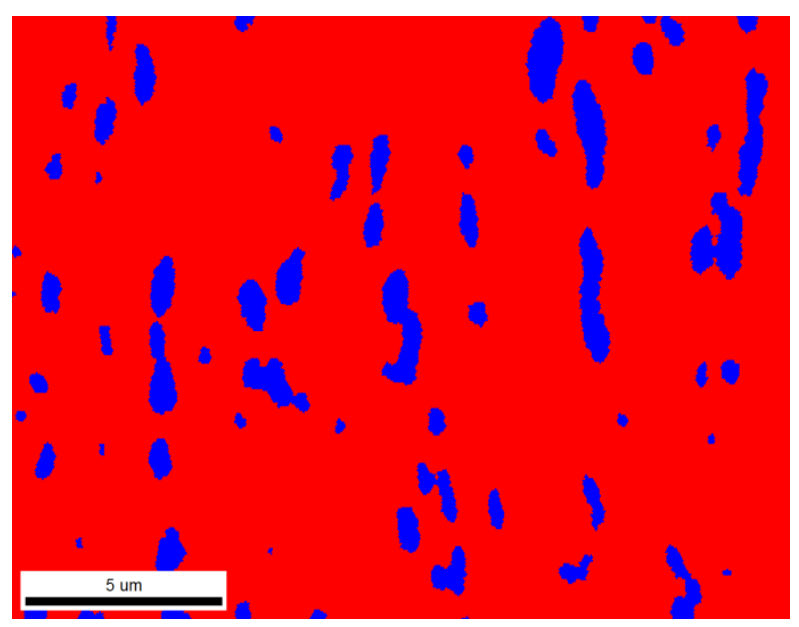

Figure 1. Phase map of the cross-section of the Kennedy Half Dollar coin. The phase map shows a distribution of $90.9 \%$ silver-rich phase (red) and $9.1 \%$ silver-copper phase (blue).
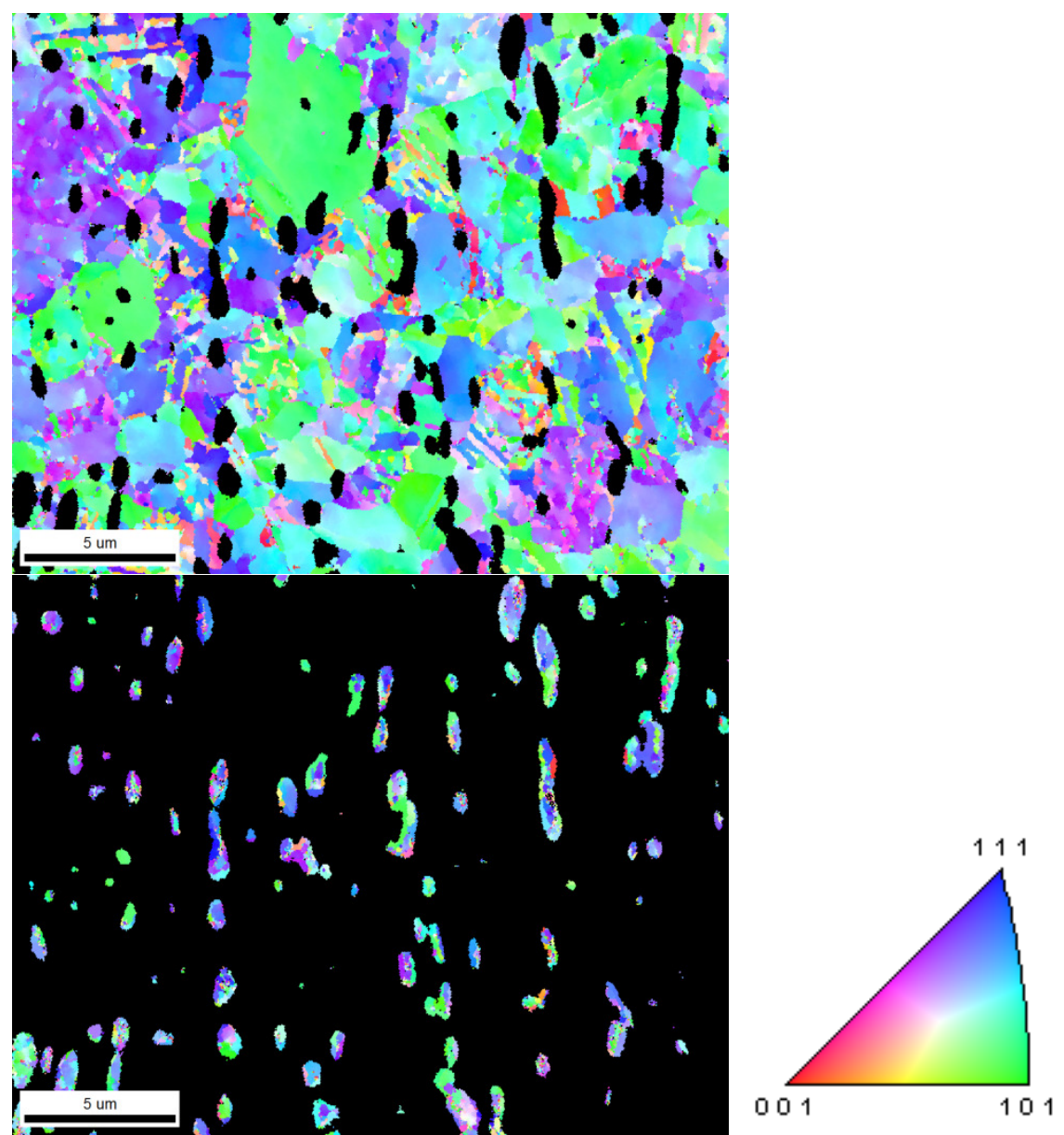

Figure 2. EBSD inverse pole figure maps of the silver-rich phase (top) and the silver-copper phase (bottom). The inverse pole figure maps shows the crystal direction that is parallel with the sample normal direction with each measurement point colored according to the stereographic triangle shown on the right. 